\title{
INFLUENCE OF SEVERE PLASTIC DEFORMATION AND SUBSEQUENT ANNEALING ON CREEP BEHAVIOUR OF MARTENSITIC 9\% CR STEEL
}

\author{
${ }^{1}$ Petr KRÁL, ${ }^{1}$ Jiri DVOŘÁK, ${ }^{1}$ Václav SKLENIČKA, ${ }^{2,3,4}$ Zenji HORITA, ${ }^{5}$ Yoichi TAKIZAWA, \\ ${ }^{6}$ Yongpeng TANG, ${ }^{1}$ Lenka KUNČICKÁ, ${ }^{1}$ Květa KUCHAŘOVÁ, ${ }^{1}$ Marie KVAPILOVÁ, \\ ${ }^{7}$ Marie SVOBODOVÁ \\ ${ }^{1}$ Institute of Physics of Materials, Academy of Sciences of the Czech Republic, Brno, Czech Republic, EU \\ ${ }^{2}$ Kyushu Institute of Technology, Kitakyushu, Japan \\ ${ }^{3}$ Magnesium Research Center, Kumamoto University, Kumamoto, Japan \\ ${ }^{4}$ Saga University, Synchrotron Light Application Center, Saga, Japan \\ ${ }^{5}$ Technology Department, Nagano Forging Co., Ltd, Nagano, Japan \\ ${ }^{6}$ WPI, International Institute for Carbon-Neutral Energy Research (WPI-I2CNER), Kyushu University, \\ Fukuoka, Japan \\ 'UJP PRAHA a.s., Prague-Zbraslav, Czech Republic, EU
}

https://doi.org/10.37904/metal.2021.4147

\begin{abstract}
The objective of the study is to evaluate the effects of severe plastic deformation (SPD) and annealing on creep behaviour of advanced tungsten modified creep-resistant $9 \% \mathrm{Cr}$ martensitic P92 steel. The as-received P92 steel was deformed by high-pressure torsion (HTP), high-pressure sliding (HPS) and rotary swaging (RS) at room temperature prior creep testing. These SPD methods imposed significantly different equivalent plastic strain in the range from 1 up to 20. Constant load creep tests in tension were performed in an argon atmosphere at $873 \mathrm{~K}$ and applied stress ranging from 50 to $200 \mathrm{MPa}$. The microstructure and phase composition of P92 steel were studied using a scanning electron microscope Tescan Lyra 3 and a transmission electron microscope Jeol 2100F.

The results show that under the same creep loading conditions the HPT and HPS-processed P92 steel exhibited significantly faster minimum creep rates, creep fracture strain and the decrease in the value of the stress exponent of the creep rate in comparison with as-received P92 steel. However, it was revealed that the RS-processed specimens exhibited one order of magnitude lower minimum creep rate and lower ductility compared to commercial P92 steel.

The creep curves for the HPT and HPS-processed states exhibited a pronounced minimum of strain rate. The pronounced minimum of strain rate disappeared when these states were annealed at $923 \mathrm{~K} / 500 \mathrm{~h}$ before application of creep loading. The microstructure changes occurring during creep and different creep behaviour between as-received and deformed states are discussed.
\end{abstract}

Keywords: Creep-resistant $9 \% \mathrm{Cr}$ steels, severe plastic deformation, creep, microstructure

\section{INTRODUCTION}

Many methods of severe plastic deformation (SPD) are known at present time, e.g. high pressure torsion (HPT), equal-channel angular pressing (ECAP), high-pressure sliding (HPS), rotary swaging (RS), etc. Due to the rapid development in this area, new methods based on SPD are emerging, which are characterized by higher efficiency of the stored strain and a larger volume of processed material. As for specific examples, the 
recently developed methods of twist channel (multi-)angular pressing (TCAP and TCMAP), continuous high pressure torsion (CHPT) and dissimilar channel angular pressing (DCAP) can be mentioned [1-3].

Creep of SPD-processed materials with ultra-fine grained (UFG) microstructure was frequently investigated on pure metals and alloys [4]. It is generally accepted that the grain size and thus number of high-angle grain boundaries (HAGBs) are one of the key parameters which significantly influence creep behaviour of SPD materials. From this reason the reduction of grain size down to UFG region leads to the greater influence of grain boundary-mediated mechanisms on creep behaviour compared to coarse-grained counterparts. At present time there are only a few reports [5] in the literature documenting the creep behaviour in creep-resistant $9 \% \mathrm{Cr}$ steels processed by SPD. Further, it was also observed that the application of SPD accelerates the phase precipitation of Laves or $\sigma$ phase in creep-resistant chromium steels. The aim of present work is to investigate the effect of various SPD processing methods and post-deformation ageing on creep resistance and creep fracture strain in P92 steel.

\section{EXPERIMENTAL METHODS AND PROCEDURES}

The experiments were conducted on advanced tungsten modified $9 \% \mathrm{Cr}$ P92 steel $[6,7]$ both on its as-received coarse-grained (CG) state and on state processed by SPD applications. The SPD states of P92 steel were prepared by deformation of the as-received state using methods HPT, HPS and RS.

HPT technique is based on deformation of a flat disc specimen by torsion straining under high pressure. An extremely large strain can be imposed into the material by increasing number of HPT rotations. The discs of $1.1 \mathrm{~mm}$ thickness and $30 \mathrm{~mm}$ diameter were cut from as-received state. Further, the discs were processed at room temperature by 1 rotation under an applied pressure of $6 \mathrm{GPa}$ and using rotation speed of $0.1 \mathrm{~mm}$ per second. The value of von Mises equivalent strain during HPT process is proportional to the radius of the disc according to the following equation [8]:

$\varepsilon_{e q}=2 \pi r N / \sqrt{3} t$

where $r$ is the distance from the disc centre, $\mathrm{N}$ is the number of turns and $t$ is the thickness of disc. The sheets with dimensions of $1.1 \mathrm{~mm} \times 10 \mathrm{~mm} \times 100 \mathrm{~mm}$ were deformed by HPS technique. HPS process was developed for microstructure refinement in sheets or rods. The specimens were placed between the upper (lower) anvil and the plunger was pushed with respect to the anvils while the samples were pressed. The plunger was pushed with respect to the surrounding anvils for the distance of 5 and $15 \mathrm{~mm}$. The equivalent strain introduced with HPS process is given by the form as [8]:

$\varepsilon_{e q}=x / \sqrt{3} t$

where $x$ is the sliding length and $t$ is the sample thickness. HPS specimens processed with a certain sliding distance $x$ were denoted as $x$ HPS (e.g. 5HPS - sliding distance $x=5 \mathrm{~mm}$ ).

RS method was used for microstructure refinement of the rods. The rod with initial diameter $\left(D_{0}\right)$ is put into four split die which rotates. The die opens and closes very quickly so that $D_{0}$ is quickly reduced to final diameter $\left(D_{n}\right)$ by means of forging. The equivalent strain imposed by RS [9] was estimated by:

$\varepsilon_{e q}=\ln \left(D_{0} / D_{n}\right)^{2}$

where $D_{0} \sim 30 \mathrm{~mm}$ was reduced down to $D_{n} \sim 15 \mathrm{~mm}$ after application of RS at room temperature. Table 1 shows the values of equivalent strain imposed to the specimens by selected methods of SPD.

Table 1 The values of $\varepsilon_{\text {eq }}$ imposed by selected methods of SPD

\begin{tabular}{|c|c|c|c|c|c|}
\hline Method of SPD & RS & $5 \mathrm{HPS}$ & $15 \mathrm{HPS}$ & $2 \times 15 \mathrm{HPS}$ & HPT \\
\hline$\varepsilon_{\mathrm{eq}}$ & 1.4 & 2.6 & 7.9 & 15.8 & $25 \pm 5$ \\
\hline
\end{tabular}


The tensile creep tests were performed at $873 \mathrm{~K}$ on the above mentioned specimens processed by different degree of plastic deformation. For comparison, the tests were also conducted on as-received state. Creep testing was conducted in an environment of purified argon with the testing temperatures maintained $\pm 0.5 \mathrm{~K}$ around the desired value.

\section{RESULTS}

\section{Influence of imposed strain on creep behaviour}

The comparison of the creep curves for strain vs. time and strain rate vs. strain for P92 processed with different imposed $\varepsilon_{\text {eq }}$ are shown in Figure 1. The creep behaviour of SPD-processed specimens changes significantly with increasing value of imposed $\varepsilon_{\text {eq. }}$.

For this reason it is difficult to compare the creep properties of all investigated states at the same applied stress. Thus Figure 1 shows the creep result measured at $100 \mathrm{MPa}$ for the specimens with imposed strain between 2.6-25 \pm 5 and at $150 \mathrm{MPa}$ for $\mathrm{CG}$ and RS state with $\varepsilon_{\mathrm{eq}} \sim 1.4$. One can see that CG state exhibits the highest creep resistance and that the creep resistance decreases with increasing imposed $\varepsilon_{\text {eq }}$ (Figure 1a). The specimens with $\varepsilon_{\text {eq }}$ higher than $\sim 8$ exhibited more or less similar creep resistance.

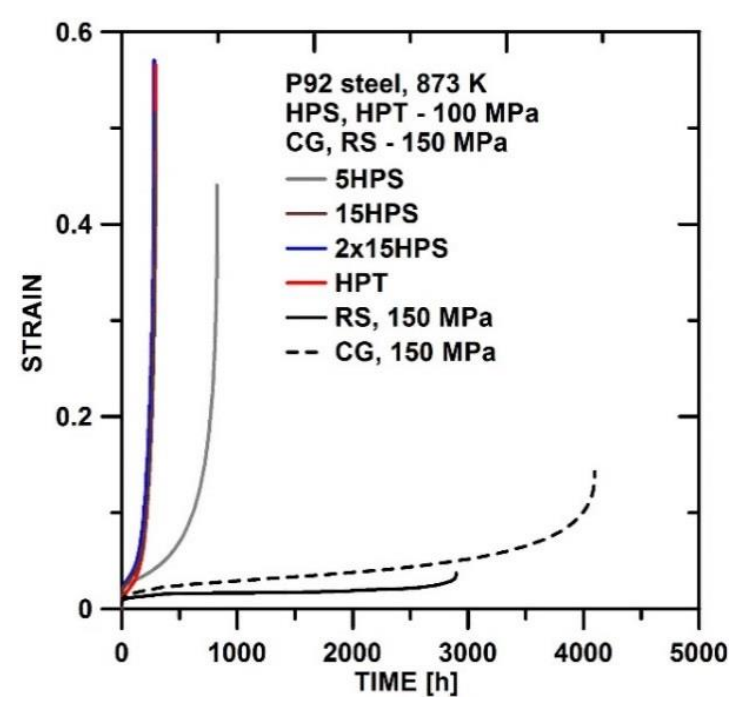

a)

Figure 1 Comparison of creep curves for samples with different imposed strain (a) strain vs. time, (b) strain rate vs. strain

Figure $1 \mathrm{~b}$ demonstrates that RS state exhibited the slowest minimum creep rate $\dot{\varepsilon}_{\text {min }}$ but also the shortest strain to fracture $\varepsilon_{f}$ in comparison with CG and other SPD-processed states. However $\dot{\varepsilon}_{\text {min }}$ is significantly faster in specimens processed by $\varepsilon_{\text {eq }}$ higher than 2 . The specimens with $\varepsilon_{\text {eq }}$ higher than 8 exhibited more or less similar $\varepsilon_{f}$ and $\dot{\varepsilon}_{\text {min }}$.

\section{Influence of post-deformation annealing on creep behaviour}

Figure 2 shows the comparison of creep behaviour of CG and 15HPS state with their annealed counterparts. One can see that the annealing at $923 \mathrm{~K}$ for $500 \mathrm{~h}$ led to the faster $\dot{\varepsilon}_{\min }$ both $\mathrm{CG}$ and $15 \mathrm{HPS}$ state and to the deterioration of creep resistance (Figure $\mathbf{2 a}$ ). 


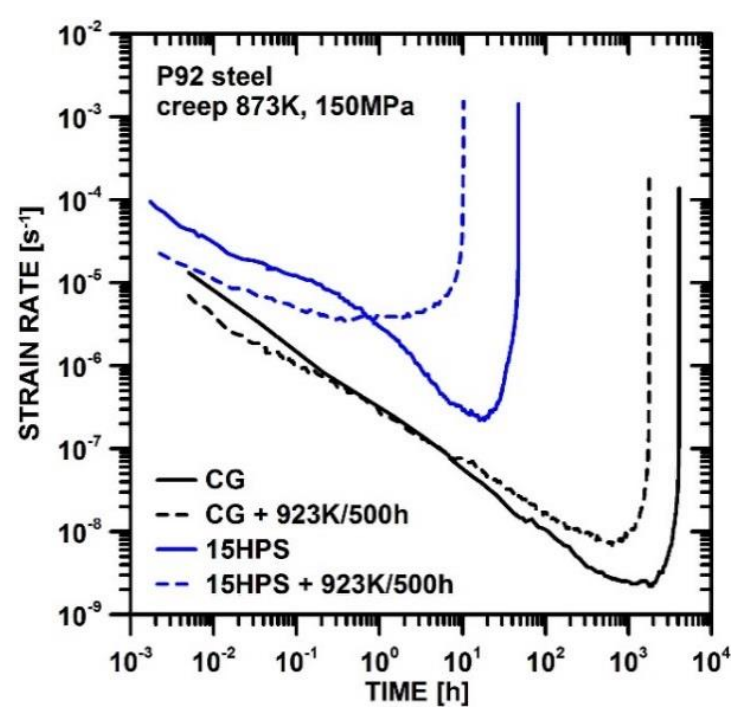

a)

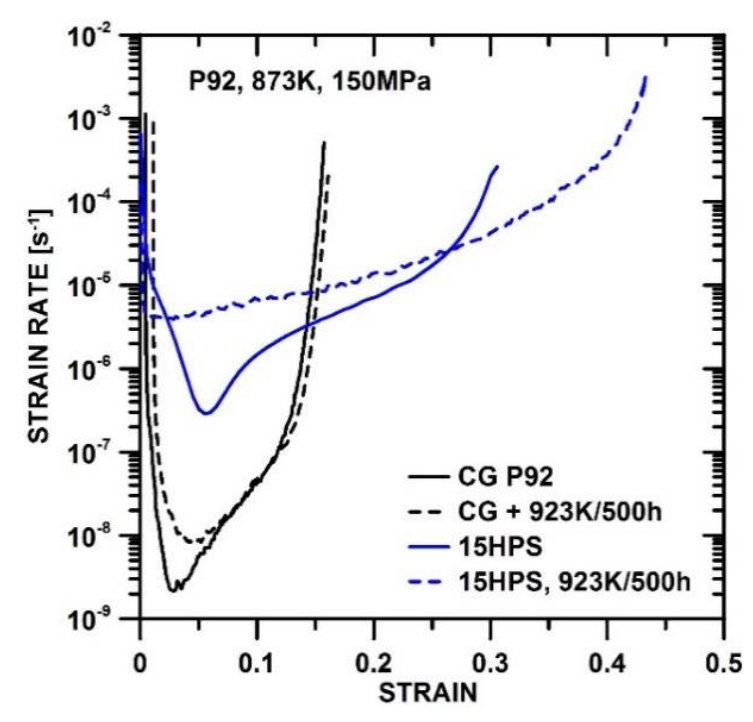

b)

Figure 2 Influence of annealing on creep of CG and 15HPS state (a) strain rate vs. time, (b) strain rate vs. strain

The results also demonstrate that the annealing provides negligible influence on $\varepsilon_{f}$ in CG state (Figure $\mathbf{2 b}$ ) with comparison of significantly improved $\varepsilon_{f}$ in 15 HPS state. It is seen (Figures 2, 3) that the annealing of HPS state changes not only creep characteristics (such as $\dot{\varepsilon}_{\min }$ or $\mathrm{t}_{\mathrm{f}}$ ) but also the shapes of the creep curves. The $15 \mathrm{HPS}$ state exhibited a pronounced $\dot{\varepsilon}_{\min }$ where the strengthening occurring during primary creep stage is followed by sudden softening (increase of strain rate) after reaching of $\dot{\varepsilon}_{\min }$. Such feature was not found in HPS state after annealing. At higher creep strains $(\varepsilon>0.1)$ the creep curves (Figure 3a) for HPS and its annealed counterpart become more or less similar.

One can observe that $\dot{\varepsilon}_{\min }$ is less pronounced at lower stresses and the differences in $\dot{\varepsilon}_{\min }$ for HPS and its annealed counterpart decreases. Figure $\mathbf{3 b}$ demonstrates that the differences in $\mathrm{t}_{\mathrm{f}}$ for HPS and its annealed counterpart also decrease. The creep resistance of HPS state after annealing was about $0.6 \mathrm{tf}$ of unannealed HPS state at $80 \mathrm{MPa}$. However, at applied stress of $150 \mathrm{MPa}$, the ratio for annealed/unannealed HPS state was about 0.2 tf only.

\section{DISCUSSION}

Creep resistance of tempered martensitic P92 steel is predominantly influenced by dislocation density, subgrain and martensitic lath boundaries which movement can be restricted by carbides and also secondary phases formed during thermal exposure [10]. However the creep resistance of CG P92 steel at $873 \mathrm{~K}$ subsequently decreases with increasing value of imposed $\varepsilon_{\text {eq. }}$. This is consequence of the transformation of CG to UFG microstructure. The martensitic boundaries $\left(111 / 60^{\circ}\right)$ and newly formed low-angle grain boundaries (LAGBs) in P92 steel are subsequently transformed with increasing $\varepsilon_{\text {eq }}$ to the new grain boundaries with random misorientation distribution [5]. The decrease of creep resistance in SPD-processed state of P92 steel could be explained by change in the proportion and distance of LAGBs and high-angle gran boundaries (HAGBs) [11]. This microstructure changes led to the higher influence of grain-boundary mediated processes such as grain boundary sliding [12], more intensive and fast diffusion processes [13,14] or enhanced dynamic recovery by HAGBs [15] on creep behaviour. The RS-processed state exhibited slower $\dot{\varepsilon}_{\min }$ (higher creep strength) than CG P92 steel. But creep resistance of RS state was lower compared to CG state. The creep results (Figure 1) suggest that it is due to low creep strain. Recently it was found that RS state contains 
significantly heterogeneous microstructure with large elongated and fine more or less equiaxed grains. It seems that the formation of heterogeneous grain microstructure and maybe heterogeneous distribution of precipitates in RS state led to the earlier occurrence of fracture processes during tensile testing compared to CG and other SPD-processed states. We can speculate that opposite results in creep resistances for CG and RS states may be found in compression creep tests at constant stress due to absence of fracture. Actually, the differences in creep behaviour for tensile and compression tests were found in pure Cu processed by ECAP [4].

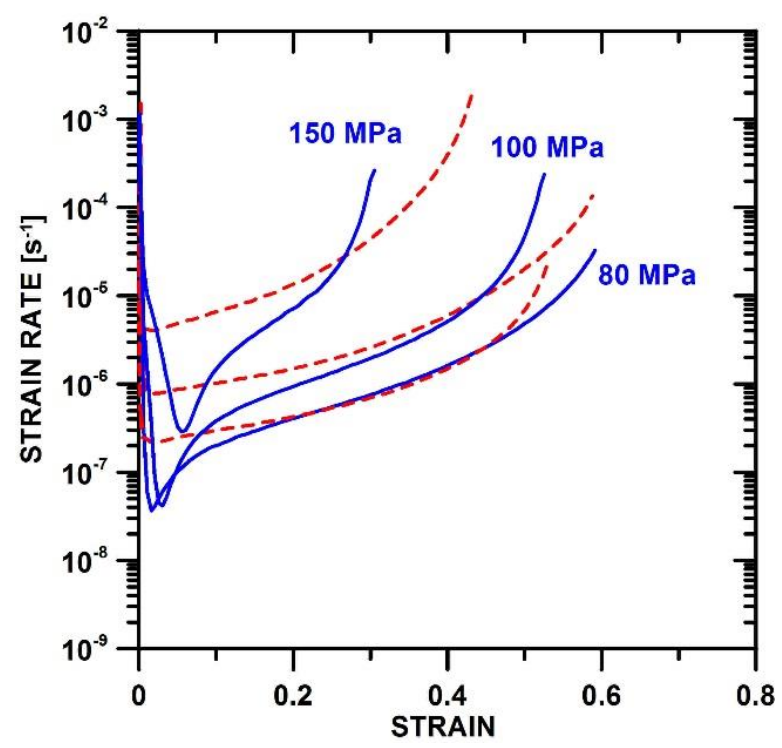

a)

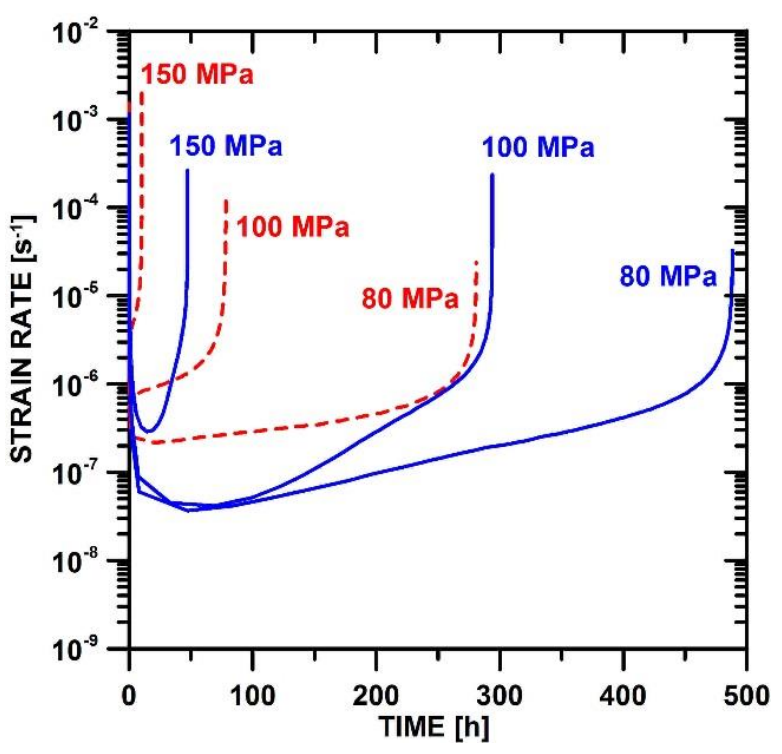

b)

Figure 3 Comparison of creep behaviour for unannealed and annealed 15HPS samples (a) strain rate vs. strain, (b) strain rate vs. time

The creep curves of $15 \mathrm{HPS}$ state exhibited a pronounced $\dot{\varepsilon}_{\min }$ which can be explained by the formation of fine Laves phase leading to the additional precipitation strengthening $[16,17]$. The fast increase of strain rate after reaching of $\dot{\varepsilon}_{\min }$ can be associated with subsequent coarsening of Laves phase and grain coarsening due to the decrease of the pinning effect of particles at boundaries. The coarsening of Laves phase, other carbides and subgrains/grains during annealing at $923 \mathrm{~K}$ for $500 \mathrm{~h}$ before creep loading can be also the reason for the decrease of creep resistance in 15HPS and also CG state.

\section{CONCLUSIONS}

The application of SPD leads to the decrease of the creep resistance in tension. HPS and HPT-processed specimens with $\varepsilon_{\text {eq }}$ higher than about 2.6 exhibit the significant improvement of strain to fracture. However the application of RS with $\varepsilon_{\text {eq }}$ about 1.4 caused the decrease of strain to fracture compared to CG state. The stressfree annealing at $923 \mathrm{~K}$ for $500 \mathrm{~h}$ led to the significant decrease of creep resistance of $15 \mathrm{HPS}$ state and caused also slight decrease of $t_{f}$ in $C G$ state.

\section{ACKNOWLEDGEMENTS}

The authors acknowledge financial support from the Czech Science Foundation (grant No. 1918725S). The work was supported in part by a grant-in-aid from MEXT, Japan, for scientific research

(A) (No. J19H00830). 


\section{REFERENCES}

[1] KOCICH, R., FIALA, J., SZURMAN, I., MACHÁČKOVÁ, A., MIHOLA, M. Twist-channel angular pressing: effect of the strain path on grain refinement and mechanical properties of copper. J. Mater. Sci. 2011, vol. 46 (24), pp. 7865-7876.

[2] BAGHERPOUR, E., PARDIS, N., REIHANIAN, M., EBRAHIMI, R. An overview on severe plastic deformation: research status, techniques classification, microstructure evolution, and applications. Int. J. Adv. Manuf. Technol. 2019, vol. 100, pp. 1647-1694.

[3] $\mathrm{KOClCH}, \mathrm{R}$. Effects of twist channel angular pressing on structure and properties of bimetallic $\mathrm{Al} / \mathrm{Cu}$ clad composites. Mater. Design. 2020, vol. 196, 109255.

[4] KRAL, P., DVORAK, J., SKLENICKA, V., LANGDON, T.G. The Characteristics of creep in metallic materials processed by severe plastic deformation. Mater. Trans. 2019, vol. 60, pp. 1506-1517.

[5] KRAL, P., DVORAK, J., SKLENICKA, V., MASUDA, T., HORITA, Y., KUCHAROVA, K., KVAPILOVA, M., SVOBODOVA, M., Microstructure and creep behaviour of P92 steel after HPT. Mater. Sci. Eng. 2018, vol. 723, pp. 287-295.

[6] ENNIS, P.J., ZIELINSKA-LIPIEC, A., WACHTER, O., CZYRSKA-FILEMONOWITZ, A. Microstructural ability and creep rupture strength of the martensitic steel P92 for advanced power plant. Acta Mater. 1997, vol. 45, pp. 49014907.

[7] HALD, J. Microstructure and long-term properties of 9-12\%Cr steels. Int.J. Press Vessel. Pip. 2008, vol. 85, pp. 30-37.

[8] VALIEV, R.Z., ISLAMGALIEV, R.K., ALEXANDROV, I.V. Bulk nanostructured materials from severe plastic materials. Prog. Mater. Sci. 2000, vol. 45, pp. 103-189.

[9] KUNČICKÁ, L., KOCICH, R., STRUNZ, P., MACHÁČKOVÁ, A. Texture and residual stress within rotary swaged Cu/Al clad composites. Mater. Lett. 2018, vol. 230, pp. 88-91.

[10] ABE, F., KERN, T-U., VISWANATHAN, R. Creep-resistant steels. Cambridge: Woodhead Publishing, 2008.

[11] BLUM, W., ZENG, X.H. A simple dislocation model of deformation resistance of ultrafine-grained materials explaining Hall-Petch strengthening and enhanced strain rate sensitivity. Acta Mater. 2009, vol. 57, pp. 19661974.

[12] LANGDON, T.G. A unified approach to grain boundary sliding in creep and superplasticity. Acta Metall. Mater. 1994, vol. 42, pp. 2437-2443.

[13] KOLOBOV, Y.R., GRABOVETSKAYA, G.P., IVANOV, M.B., ZHILYAEV, A.P., VALIEV, R.Z. Grain boundary diffusion characteristics of nanostructured nickel. Scr. Mater. 2001, vol. 44, pp 873-878.

[14] DIVINSKI, S.V, REGLITZ, G., RÖSNER, H., ESTRIN, Y., WILD, G. Ultra-fast diffusion channels in pure Ni severely deformed by equal-channel angular pressing. Acta Mater. 2011, vol. 59, pp. 1974-1985.

[15] BLUM, W., LI, Y.J., ZHANG, Y., WANG, J.T. Deformation resistance in the transition from coarse-grained to ultrafine-grained $\mathrm{Cu}$ by severe plastic deformation up to 24 passes of ECAP. Mater. Sci. Eng. A. 2011, vol. 528, pp. 8621-8627.

[16] ABE, F. Creep rates and strengthening mechanisms in tungsten-strengthened $9 \mathrm{Cr}$ steels. Mater. Sci. Eng. A. 2001, vol. 319-321, pp. 770-7723.

[17] SHIBUYAN, M., TODA, Y., SAWADA, K., KUSHIMA, H., KIMURA, K. Effect of precipitation behavior on creep strength of $15 \% \mathrm{Cr}$ ferriticsteels at high temperature between 923 and 1023 K. Mater. Sci. Eng. A. 2014, vol. 592, pp. 1-5. 